Sharif University of Technology
Scientia Iranica
SCIENTIA
I RAN I CA
http://scientiairanica.sharif.edu

\title{
Life-cycle cost analysis of RC bridges subjected to multiple hazards
}

\author{
P. Asadi ${ }^{a, *}$, S. Hamed Ranjkesh ${ }^{\mathrm{b}}$, and A. Zeinal Hamadani ${ }^{\mathrm{b}}$ \\ a. Department of Civil Engineering, Isfahan University of Technology, Isfahan, 84156-83111, Iran. \\ b. Department of Industrial and Systems Engineering, Isfahan, 84156-83111, Iran. \\ Received 9 November 2018; received in revised form 14 December 2019; accepted 10 February 2020
}

\author{
KEYWORDS \\ Uncertain natural \\ hazards; \\ Reinforced concrete \\ bridges; \\ Life-cycle cost \\ analysis; \\ Cost-benefit analysis; \\ Seismic effects.
}

\begin{abstract}
The main structural elements of Reinforced Concrete (RC) bridges deteriorate with time under uncertain hazards such as scouring and corrosive conditions. In this paper, a multi-hazard framework is proposed to assess the performance of bridges subjected to the main effective uncertain natural hazards during their lifetime. In this assessment, the uncertainties associated with the combined effects of multiple hazards including pier scour, earthquake, carbonation, and corrosion are considered. Therefore, for each, hazard their severity relationships have been extracted over time, and the effects of these hazards on concrete elements are presented as resistance dimming parameters. The annual and cumulative losses due to these hazards in unit of currency are estimated using the life-cycle cost analysis. For decision making, the value of the expected cumulative cost associated with the retrofit or design scenarios is evaluated using a cost-benefit analysis. The results for a case study bridge, obtained from the framework proposed in the present study, indicated the significant impact of the different scenarios on reducing the expected value of damages or incurred losses due to multiple hazards.
\end{abstract}

(C) 2021 Sharif University of Technology. All rights reserved.

\section{Introduction}

A considerable body of research has been recently devoted to the probabilistic assessment of Reinforced Concrete (RC) and steel structures under various hazards such as deterioration, corrosion, carbonation, wind loads, airborne chloride, fatigue, traffic loads, earthquakes, and flood-induced scour. For structures under time-dependent hazards, a life-cycle analysis should be performed by considering multiple hazards rather than individual ones.

Some studies investigated the probability of bridge failure due to certain hazards including airborne

\footnotetext{
*. Corresponding author. Tel.: +983133913806;

Fax: +983133912700

E-mail address: asadi@cc.iut.ac.ir (P. Asadi)
}

chloride and traffic loading. Deco and Frangopol [1] introduced a framework for evaluating the possible risks arising from the earthquake and abnormal traffic loads for the serviceability of a bridge in its life-cycle. The authors also used a fragility analysis to evaluate the effects of seismic hazards incurred on bridge lifetime. Zhu and Frangopol [2] developed a methodology for assessing the time-variant risk associated with the closure of bridge lanes due to traffic loading and scour. The lane-closure events were evaluated on the basis of girder and pier column failures due to scour.

The vulnerability of bridges to seismic and scour attacks have been studied extensively. Alipour et al. [3] analyzed nine types of two-span RC bridges to derive five seismic fragility curves for a range of scour depths in terms of Peak Ground Acceleration (PGA). The study showed that, for a given value of PGA, the probability of bridge failure increased with scour depth rising. Wang et al. [4] considered three types of RC bridges to 
analyze the effects of scouring on the seismic response of bridges using fragility curves. The curves showed that scour had considerable effects on the capacities of the principal bridge components. Guo and Chen [5] developed a nonlinear pushover-based soil-foundationbridge simulation model to assess the effects of seismic loads and flood-induced scour on bridge failure during its service life. Guo et al. [6] used a time-dependent seismic fragility analysis to evaluate the performance of bridges under scour-induced erosion and earthquake loads while also considering the uncertainty of scouring hazard and its time-dependence.

Research efforts have also been directed toward the study of deterioration impacts on the seismic response of bridges $[7,8]$. Cui et al. [8] estimated the timedependent seismic fragility of RC bridge substructures using an improved reinforcement deterioration model. Akiyama et al. [9] proposed a new computational approach for investigating the effect of airborne chloride on the life-cycle seismic reliability of bridge piers. In their approach, the probability of RC bridge failure increases as a result of exposure to multi-hazards. Dong et al. [10] presented a framework for assessing bridge sustainability under flood-induced scour and seismic hazard with due heed paid to the effects of structural deterioration. It was quantitatively shown that deterioration and scour hazards were able to cause severe reductions in structural capacity. Kumar et al. [11] investigated the effects of structural deterioration caused by cumulative damages due to earthquake and corrosion on the life-cycle of RC bridges erected in earthquake-prone regions. Biondini et al. [12] conducted a probabilistic nonlinear static analysis to predict the lifetime seismic performance of concrete bridges subjected to corrosion. They also investigated the time-variant reductions in the cross-sections of piers under aggressive environmental conditions. Shekhar et al. [13] presented a framework to assess the seismic life-cycle of highway bridges subjected to chlorideinduced deterioration. They investigated the impact of exposure condition and chloride-induced corrosion on the seismic behavior of highway bridges. Gheitasi and Harris [14] investigated the effect of corrosioninduced subsurface deck delamination on the performance of steel-concrete bridges using finite element analysis.

Life-Cycle Cost Analysis (LCCA) is considered as one of the effective tools for quantitative risk analysis which explicitly considers the consequences of earthquake events in terms of seismic induced losses. It is mostly used to achieve optimal designs of different types of structure and seismic risk mitigation decision [15]. The LCCA and life-cycle assessment of the structures are an important area of research in bridge rehabilitation through design and retrofit plans [16-22].

Koeleian et al. [16] developed an integrated life- cycle assessment and LCCA model aimed at increasing the sustainability of the bridges. Frangopol [19] investigated the challenges in the life-cycle performance of infrastructure systems in terms of their assessment, monitoring, management, maintenance, and optimization in view of existing uncertainties. Ranjkesh et al. [22] proposed a framework for the collapse assessment of deteriorating bridges under multi-hazard conditions during their life-cycle using fragility curves. They scored the damage probabilities to make an engineering decision regarding different scenarios. In a research performed by $\mathrm{Li}$ and $\mathrm{Li}$ [23], the engineers' (as decision-makers) preference information based on the incorporation of theoretical assessment and engineering experience is integrated to generate the value function and to drive the search for the expected performance objectives of life-cycle seismic design.

Retrofitting of brides has been the focus of many studies [24]. The performance of retrofitted bridges under natural hazards was evaluated based on the probabilistic economic losses during their lifecycle $[25,26]$. Moreover, the results of retrofit plans for bridge performance under seismic loads were evaluated using the life-cycle cost-benefit analysis [18-20].

The conclusion of previous studies suggests that a framework is required for life-cycle analysis of bridges that are subjected to the uncertain natural hazards and corrosive conditions in their lifetime. The most important use of this framework relates to make decisions between retrofitting or refurbishing options. In previous studies, uncertain hazards and corrosive conditions have not been integrated and the effects of these considerations have not been evaluated in decision making.

Time-dependent information on scour, earthquake events and corrosion are essential for developing strategies for bridge design, maintenance, and repair. A more accurate picture of the risk of $\mathrm{RC}$ bridges exposed to natural hazards during their life-cycle might be obtained if the correlations between bridge responses to structural deterioration due to such mechanisms as earthquake and pier scour are known beforehand. The main innovation of this study is the development of a comprehensive framework for performance-based bridge design rehabilitation under a multi-hazards condition including earthquake, pier scours, corrosion, and carbonation. To achieve this goal, a LCCA is also developed to predict the performance of bridges during their lifetime. Also, this paper serves retrofit plans to mitigate seismic vulnerability of the existing bridges under multi-hazard condition in such regions. A benefit-cost analysis procedure is provided to evaluate the retrofitting strategies in the life-cycle of the bridge. The study uses an RC bridge located in an earthquakeprone region where there is also a potential risk of bridge deterioration and scour. 


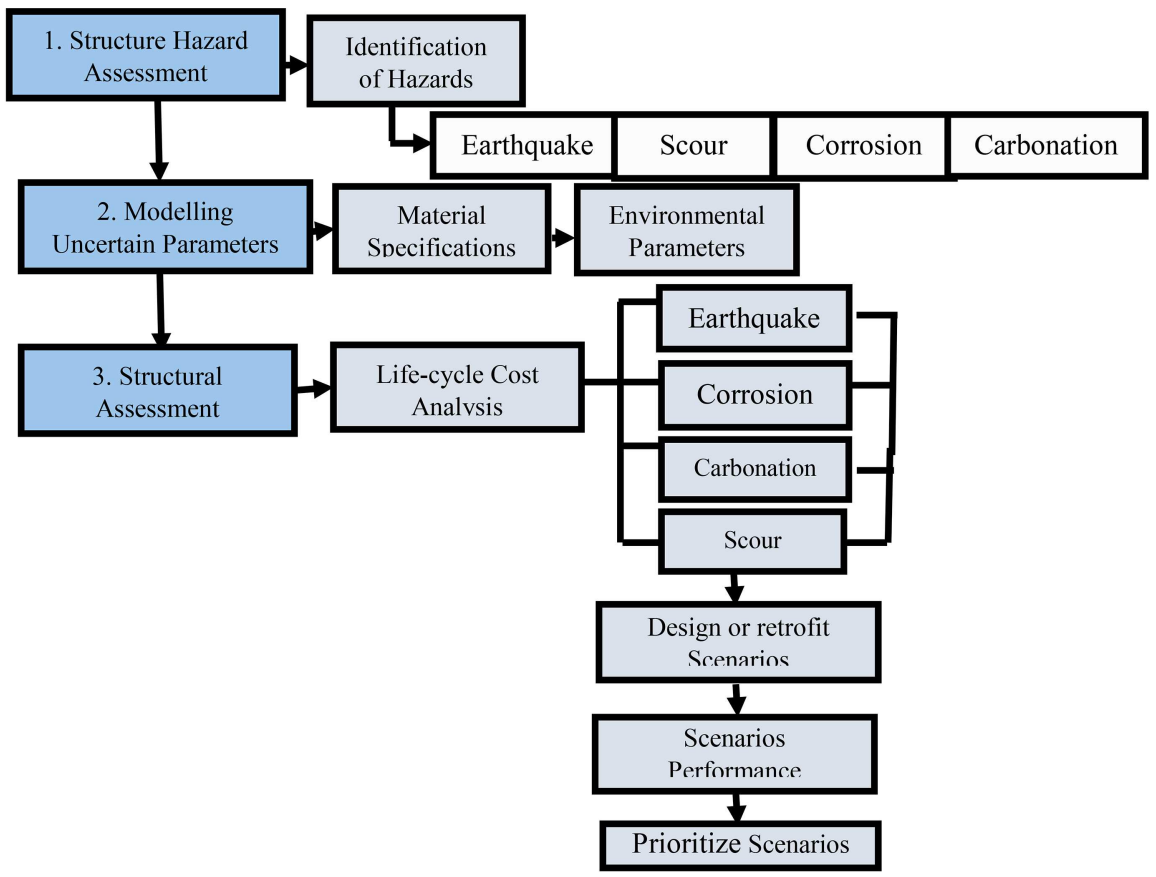

Figure 1. Life-cycle multi-hazard framework for bridges.

\section{Life-cycle multi-hazard framework for bridges}

A general framework was developed to evaluate design or retrofit scenarios based on environmental uncertainties and hazards, through the LCCA (Figure 1).

In the life-cycle analysis, it is important to determine all the hazards which poses threats to the structure. Some hazards such as earthquake can be of extreme magnitudes, leading to significantly increased structural vulnerability. One of the most severe forms of structurally damaging scour is the local one as it causes considerable strength losses in bridge foundation or its abutment that is obviously detrimental to bridges located in earthquake-prone areas [3]. The performance of bridges built across rivers may be influenced by scours around their piers during flood events or rushing streams. Proper and accurate evaluation of the effects of scour is, therefore, of utmost importance to bridge service life analysis or bridge design rehabilitation plans.

Corrosion is a continuous process which can lead to deterioration of structural components and their increased vulnerability against such extreme events as seismic loads and floods. Another major reason for bridge deterioration is the carbonation process, which is the chemical reaction between carbon dioxide present in the air and the hydrated calcium of cement in $\mathrm{RC}$ structures. According to Ghosh and Padgett [27], bridge deterioration definitely increases the vulnerability of most critical components. Because of the deterioration-induced uncertainties in the prediction of bridge performance under seismic or service loads, strength losses due to deterioration need to be estimated stochastically.

\section{Hazards identification}

In order to evaluate the life-cycle cost of the bridges, the hazard processes accounting for relevant uncertainties must be identified. In this section, the hazards that might affect bridge performance are described.

\subsection{Probabilistic models of reinforcement corrosion}

Deterioration is the process through which the strength of the structural components are considerably degraded and their vulnerability to extreme loads and conditions as earthquakes, traffic loads, floods, and scours increased [28]. The process might have significant impacts on the seismic response of bridges [29]. Investigation of the performance of a deteriorating bridge under a seismic load may yield inaccurate results if bridge deterioration is not duly considered in the analysis. One of the most common mechanisms contributing to the deterioration of $\mathrm{RC}$ bridges is corrosion due to exposure of the reinforcement to chloride ions [28]. The reinforcement bars can be corroded by two different levels of exposure to chlorides: atmospheric and splash. Atmospheric corrosion occurs when the ambient humidity contains chloride ions and splash corrosion occurs where the structure is exposed to the chloride ions of salt water [29].

In concrete structures, corrosion mainly reduces 
the cross-section area of the reinforcing steel bars [29]. The time-variant reduction in the diameter of the steel reinforcement due to corrosion can be captured by the Eq. (1) [25,27]:

$$
d_{b}(t)= \begin{cases}d_{b 0} & t \leq T_{\text {corr }} \\ d_{b 0}-\frac{(1-w / c)^{1.64}}{d_{c}}\left(t-T_{\text {corr }}\right)^{0.71} & T_{\text {corr }}<t \\ 0 & t>T_{f}\end{cases}
$$

where $d_{b}(t)$ is the diameter of the steel bar at time $t$; $w / c$ is the water-to-cement ratio, which is considered to be variable; $d_{c}$ is the reinforcement cover depth; $T_{f}$ is the time at which the steel bar diameter theoretically reaches zero [30]:

$$
T_{f}=T_{c o r r}+d_{b 0}\left(d_{c} / 1.0508(1-w / c)^{-1.64}\right)^{1 / 0.71},
$$

where $T_{\text {corr }}$ is the corrosion initiation time when chloride concentration at the concrete surface reaches its critical level at the depth of the reinforcing bars and can be expressed by Eq. (3) [27,29]:

$$
\begin{aligned}
T_{\text {corr }}=X_{I} & \left\{\frac{\left(d_{c}\right)^{2}}{4 K_{e} K_{t} K_{c} D_{c}\left(t_{r e f}\right)^{n}}\right. \\
& {\left.\left[e r f^{-1}\left(1-\frac{C_{c r}}{C_{c s}}\right)\right]^{-2}\right\}^{1 /(1-n)}, }
\end{aligned}
$$

where $C_{c r}$ is the critical chloride concentration, erf is the error function, $X_{I}$ is a model uncertainty coefficient to account for the idealization by Fick's second law, $K_{e}$ is an environmental factor to consider ambient conditions, $K_{t}$ is a factor for representing the influence of test methods to determine the empirical diffusion coefficient $D_{c}, K_{c}$ is a parameter that accounts for the influence of curing, $t_{r e f}$ is the reference period for $D_{c}$, and $C_{c s}$ is chloride concentration on the surface defined as a linear function of the variable water-tobinder ratio $w / b$. This latter parameter is obtained from the relation $C_{c s}=A_{C S}(w / b)+\varepsilon_{C S}$ in which $A_{C S}$ and $\varepsilon_{C S}$ are model parameters. This paper focuses on the evaluation of the loss of reinforcement area due to corrosion in $\mathrm{RC}$ bridges during the propagation phase. The secondary effects of corrosion in RC structures such as gradual cracking, spalling, and pitting process [11] are ignored in the current study.

\subsection{Carbonation process}

Carbonation is the chemical reaction between the carbon dioxide present in the air and the hydrated calcium of the cement in concrete. The process starts immediately after concrete is exposed to air. The carbon dioxide in the atmosphere penetrates into the concrete through its pores and reacts with the calcium hydroxide and moisture to form calcium carbonate [31].
This process leads to changes in the physical and chemical properties of cementitious materials. Carbonation can reduce the natural alkalinity of concrete from a $\mathrm{pH}$ level of 13 to about $9(\mathrm{pH} \approx 8.3)$, while a high $\mathrm{pH}$ creates a passive layer around the steel. At $\mathrm{pH}$ values less than 9 , the passive layer breaks and the reinforcement steel will be more vulnerable to the corrosive effects of water and air and corrosion occurs [32]. Therefore, the protective cover reduces in concrete reinforcement with time due to carbonation [33,34]. The carbonation-induced corrosion embedded reinforcing bars. The carbonation process can be expressed from Fick's first law of diffusion as Eq. (4) [32]:

$$
C(t)=K(t)^{0.5}
$$

where $C(t)$ is the depth of carbonation $(\mathrm{mm}), t$ is the exposure time (months), and $K$ is the carbonation coefficient $\left(\mathrm{mm} /\right.$ month $\left.^{0.5}\right)$.

\subsection{Scour hazard analysis}

Flowing water or flooding events may remove the soil around the bridge foundation. This phenomenon is called bridge scour. In extreme conditions such as flood or rushing streams, the depth of the scour may develop considerably and affect the rigidity of the base, which may lead to a significant reduction of pier strength and increments in damages.

For a deterministic calculation of the scour depth, an equation is represented by the Federal Highway Administration (FHWA) [35] for live-bed and clearwater situations:

$$
D_{s}=2.0 y_{p} K_{1} K_{2} K_{3} K_{4}\left(\frac{B}{y_{p}}\right)^{0.65} F_{r}^{0.43},
$$

in which $D_{s}$ is estimated scour depth; $y_{p}$ is flow depth just upstream of the pier, and $B$ is the bridge pier width. $K_{1}, K_{2}, K_{3}$, and $K_{4}$ are correction factors accounting for the nose shape of the pier, the angle between the flow direction and the pier direction; streambed conditions, and bed material size, respectively. The values for these four correction factors can be obtained from the tables in FHWA [35]. $F_{r}$ is the Froude number upstream the pier:

$$
F_{r}=V /(g y)^{1 / 2},
$$

where $V$ is the mean flow velocity and $g$ is gravity acceleration. The relationship between the flow depth just upstream the pier, $y_{p}$, and the flow discharge rate, $Q$, for a triangular open channel can be defined as Eq. (6):

$$
Q=\frac{b y_{p}}{n}\left(\frac{b y_{p}}{b+2 y_{p}}\right)^{0.67} S^{0.5}
$$

in which $b$ is the river width; $n$ is the Manning roughness coefficient, and $S$ is the slope of the bed stream. 
The flow velocity can be calculated using the Manning equation [36]:

$$
V=\frac{1}{n} R^{0.67} S^{0.5}
$$

where $R$ is the hydraulic radius. Johnson $[37,38]$ analyzed a range of flow depth to pier width ratios and showed that the average observed scour depth was lower by a factor of 0.57 than that estimated by Eq. (5). Hence, a model correction factor, $\lambda_{p}$, was introduced into the equation, which is considered to have a lognormal distribution with a mean value of 0.57 and a Coefficient Of Variation (COV) equal to 0.6 [39]. The uncertainties related to the other model parameters were also addressed. The correction factor for nose shape, $K_{1}$, the correction factor for the angle of attack, $K_{2}$, and the correction factor for bed material size, $K_{4}$, usually have deterministic values in the literature. Johnson [37] suggested a normal distribution with a mean value of 1.10 and a COV of 0.275 for the correction factor of streambed condition, $K_{3}$. Also, the possible uncertainties associated with channel features have been accounted for using the three probability distributions of log-Pearson Type III distribution, lognormal distribution, and extreme Type I distribution to model discharge rate, $Q$, in Eq. (6) [40].

Finally, the scour probability can be calculated by the following limit-state equation for the scour depth, $D_{p}$ :

$P_{\text {scour }}=P\left[D_{p}<2.0 \lambda_{p} y_{p} K_{1} K_{2} K_{3} K_{4}\left(\frac{B}{y_{p}}\right)^{0.65} F_{r}^{0.43}\right]$

in which $D_{p}$ is the scour depth. If the probabilistically estimated scour depth exceeds the critical threshold, $D_{p}$, scour occurs. Monte Carlo simulation is used to estimate this probability.

\subsection{Seismic hazard}

The hazard curve that is often generated by Probabilistic Seismic Hazard Analysis (PSHA) is used for vulnerability assessment of structures. For this purpose, a regional seismicity historic earthquake and ground motion dataset are collected. The annual exceedance probabilities of earthquake event from the various intensity levels are summed up in the hazard curve. These curves are utilized for life-cycle analysis of the bridges while the combined effects of scouring, corrosion, and carbonation hazards are taken into account.

\section{Objective function based on the life cycle cost analysis}

The economic consequences due to damage levels from different seismic, scour, deterioration, and carbonation hazards for the bridge life-cycle are explored with due consideration of the combined losses incurred. Economic losses in a structure can be divided into:

1. Direct ones due to structural damages;

2. Indirect ones due to a variety of situations such as injuries, deaths, and traffic [41].

The total economic losses in a structure can be, therefore, obtained by considering both direct and indirect damages arising from an incurred hazard.

An earthquake event may lead to catastrophic disasters, injuries, deaths, insecurity, etc. These indirect costs may even exceed the direct costs related to the damages to the structure. In this study, the indirect economic losses and the downtime cost of retrofitting operations are not considered. Because, in fact, they are also related to structural damages, they only increase the damage cost as the structural loss and have no effect on the final conclusions.

Accordingly, the total cost of a bridge, $C L_{T}$, is defined as the present value of total economic losses due to structural damages to the bridge arising from multiple hazards such as the earthquake, scour, corrosion, and carbonation.

The life-cycle cost of a structure is the entire cost, including operational and maintenance cost, of a structure over its expected lifetime. LCCA is an effective tool used to deal with incurred or probably incurred resource allocation problems at the design, construction, and operation (e.g., maintenance and inspection decisions) stages [9]. The general formula for calculating the expected total life-cycle cost of a structure in this study may be defined as follows $[9,34,42]$ :

$$
E[L C C(T)]=C_{I}+C L_{T},
$$

in which:

$$
\begin{aligned}
C L_{T}= & \int_{o}^{\tau} \frac{1}{(1+r)^{t}}\left(\sum_{i=1}^{n} \sum_{j=1}^{m} C L S(i, j, t) P_{i} P_{j}(t) P_{s}(t)\right. \\
& \left.+\sum_{i=1}^{n} \sum_{j=1}^{m} C L(i, j, t) P_{i} P_{j}(t)\left(1-P_{s}(t)\right)\right) d t
\end{aligned}
$$

where $\tau$ is the time horizon considered for operating the structure; $C_{I}$ is the initial construction cost of the structure; $n$ is the number of different probable magnitudes of earthquake; $m$ is the number of damage levels caused by corrosion with carbonation effects also included; $C L S(i, j, t)$ is the function for total loss in the structure incurred by earthquake, corrosion, carbonation, and scour at time $t ; P_{i}$ is the occurrence probability of earthquake with magnitude $i ; P_{j}(t)$ is the probability that the accumulated damage caused by both corrosion and carbonation processes exceeds a certain level $j$ at time $t ; C L(i, j, t)$ is the function 
for total loss caused by earthquake, corrosion, and carbonation damages to the structure at time $t$ without any probability of scour; and $r$ is the discount rate. Also, $P_{s}(t)$ is the probability that the scour depths be greater than the buried depth of the foundation surface at time $t$. It is noticed that all the losses are considered in terms of $C_{I}$. The threats are mentioned natural hazards and their impact on bridge seismic life-cycle cost are considered in both terms of independent and combined modes depending on the type of hazard.

Ghasemi and Nowak [43] categorized the target reliability as follows: the minimization of the total expected cost, maximization of utilities, and minimization of human casualties and environmental damage. They proposed the following equation as the objective function to compute the target reliability:

$$
\begin{aligned}
\min _{\beta}= & \left\{C_{I}(\beta)+\sum_{i=1}^{n}\left(C_{M}(\beta, t)\right)_{i}\left[P_{d}(\beta, t)\right]_{i}\right. \\
& \left.+C L_{T}(\beta, t)\left[P_{f}(\beta, t)\right]\right\},
\end{aligned}
$$

where $\beta$ is the reliability index, $C_{M}$ is the maintenance cost, $\left[P_{d}\right]_{i}$ is the probability of the structural deterioration at the $i$ th sequence out of the $n$ required maintenance periods during the structural life-time, and $P_{f}$ is the probability of failure. In this paper, $C_{M}$ is the retrofit cost, which is added to Eq. (9) as a deterministic parameter.

\section{Seismic vulnerability assessment of bridges}

To perform life-cycle analyses of the bridges, it is first necessary to perform seismic vulnerability assessment of their structures. A linear and nonlinear (pushover) static analysis was employed for the service loads and for calculating the capacity curves, respectively. Therefore, a finite element computer code SAP2000 NL [44] was used for nonlinear analysis in this study. The main elements of ordinary bridges are solid decks and $\mathrm{RC}$ piers. The $19 \mathrm{~m}$ wide bridge decks consist of concrete slabs laid over the concrete box girders, which create a rigid diaphragm under the seismic loads. The connection of the piers with the decks are such that the moment does not transfer between the two elements. In modeling the piers in the SD section, the section and reinforcements have been modeled with exact dimensions and right positions. Plastic hinges may develop at both ends of the piers due to the generated seismic excitation. Momentrotation relationships at the plastic hinges generate a complex hysteretic behavior. To tackle the nonlinearity behavior of moment-rotation hinges at both ends of bridge piers, bilinear springs are used $[45,46]$. The general shape of the plastic hinges are assumed in accordance with ATC-40 [47].

ATC40 [47] is a 1996 guideline, however, it is still widely used, since it is in accordance with correct concepts. Capacity curves are developed to represent structural displacement within or beyond the elastic limit. A pushover analysis is performed to compute the total shear force created at bridge supports based on structure displacement, and to form capacity curves. The capacity spectrum method $[46,47]$ requires that the obtained capacity curve be converted into the capacity spectrum in the acceleration displacement response spectra format. The acceleration displacement response spectra represents the variation of spectral acceleration $\left(S_{a}\right)$ with spectral displacements $\left(S_{d}\right)$, which are the maximum values of absolute acceleration and displacement of a single degree of freedom system under a specific damping ratio, respectively [46]. The intersection point of the capacity spectrum and demand spectrum is defined as the performance point.

To consider the dissipation energy in the structure through nonlinear behavior beyond the yield point, the elastic demand curve of an earthquake ground motion should be reduced using a proper reduction factor. ATC-40 [47] presents certain reduction factors for a range of constant peak spectral accelerations and constant peak spectral velocities. The reduction factors are $S R_{A}$, and $S R_{V}$ which are the range before and after the soil time period. The equations for these reduction factors are as follows:

$$
\begin{aligned}
& S R_{A}=\frac{3.21-0.68 \ln \left(\beta_{e f f}\right)}{2.12}, \\
& S R_{V}=\frac{2.31-0.41 \ln \left(\beta_{e f f}\right)}{1.65},
\end{aligned}
$$

where $\beta_{\text {eff }}$ is equivalent effective viscous damping that is associated with a displacement of performance point, defined as follows:

$$
\beta_{\text {eff }}=K \beta_{0}+5 \text {, }
$$

where $\beta_{0}$ is hysteretic damping represented as equivalent viscous damping, and is damping modification factor. Bridge damage states are calculated using the rotational ductility obtained at plastic hinge region relative to the threshold rotational ductility demand at each damage level.

\section{Structural modeling and multi-hazard identification}

The framework for LCCA of bridges subjected to multihazards presented in this study is applied to a case study in order to evaluate the proposed retrofit plans and select an efficient retrofitting program. In this way, the framework procedure and its effectiveness are described. 


\subsection{The case study bridge}

The Zayandehrood River, running through the city of Isfahan as one of the largest metropolitan cities in Iran, divides the city into two neighborhoods. One of the rather important urban bridges across the Zayandehrood, Azar Bridge was built in 1976 for vehicle transport across the river. The bridge has 6 spans each $24.4 \mathrm{~m}$ long. In the transverse direction, there are three diamond-shaped piers in each support. The structural system consists of single piers and concrete reinforcement decks on simple supports. For resistance against transverse loads, special details outside the external piers are employed. A general photo and the plan of Azar Bridge, as well as the general elevation and typical sections of the piers, are presented in Figure 2. The percentage of vertical bars of piers is about $0.5 \%$, which is less than the minimum $(1.0 \%)$ steel ratio allowed in design codes [48]. According to non-seismic design codes for bridges, the minimum amount of vertical reinforcement should be adequate to develop a factored flexural resistance beyond the cracking moment and 1.33 times the factored moment required by the load combinations [49]. The available flexural capacity of the investigated bridge piers, as with most bridges

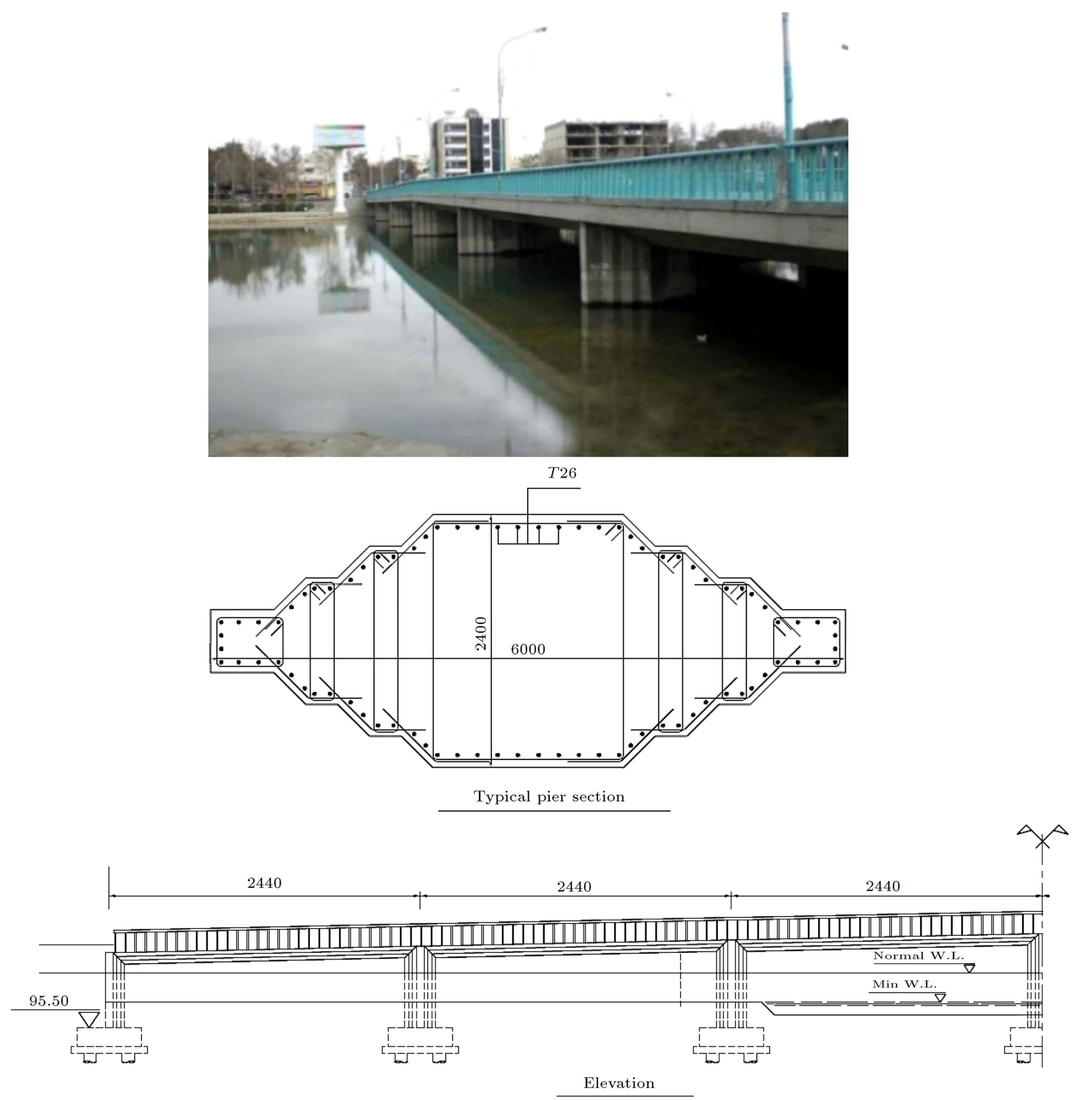

Figure 2. A schematic view of the case study of Azar Bridge. 
built at the same time, has this capacity but does not have the minimum reinforcement required by the seismic code. This deficiency made the behavior of the piers brittle and requires retrofitting. The bridge piers are under marine splash exposure when the mentioned river frequently impacts the bridge piers. Therefore, the bridge is subjected to drying and wetting cycles of salt water which contains chloride ions.

The water quality of the Zayandehrood River and the air quality of the Isfahan city is described in Table 1. According to this Table, conditions for the deterioration of concrete including corrosion under chloride ions and the carbonation process are provided.

The bridge was analyzed by subjecting it to all the service and seismic loads in the SAP2000 NL software. Service loads include the dead loads from the structural and non-structural components as well as live loads of vehicles according to AASHTO [49]. Pier sections were reproduced in exact detail using the $\mathrm{SD}$ section that also defines the concentrated plastic hinges at both ends of the elements of piers.

No serious damage is presently detected in the bridge by visual inspection. The presently visible corrosion and scours have no significant effects on the bridge although their propagation might reduce its strength in future.

\subsection{Seismic hazard and vulnerability analysis of the bridge}

There are 12 main faults capable of producing threatening ground motions at the site of the bridge. The deterministic seismic hazard analysis for this bridge site can be captured by Eq. (15) [50,51]:

$$
\log A=a M_{W}+b X-\log X+c_{i} s_{i}+\sigma_{p}
$$

in which, $A$ represents PGA $\left(\mathrm{m} / \mathrm{s}^{2}\right), M_{W}$ is the maximum accepted moment magnitude, $X$ is the distance to fault $(\mathrm{km}), \sigma_{p}$ is a probabilistic coefficient with an average value of zero, and $s_{i}$ is the soil condition coefficient. The terms $a, b$, and $c_{i}$ are constant coefficients with values of $0.399,-0.0019$, and -1.020 , respectively, for horizontal components at the site. The deterministic PGA values for a return period of 1000 years obtained from Eq. (15) for all the active faults are presented in Table 2. The probabilistic seismic hazard curve for the study site is generated based on this information.

The alignment of the piers and the presence of deep transverse beams on the bridge have enhanced its strength along the transverse direction, hence the evaluation of the bridge under the earthquake in the transverse direction is not decisive. But in the

Table 1. The water quality of the Zayandehrood River and the air quality of the city of Isfahan.

\begin{tabular}{|c|c|c|c|c|c|c|}
\hline & \multicolumn{3}{|c|}{ Water quality } & \multicolumn{3}{|c|}{ Air quality } \\
\hline & $\mathbf{P H}$ & $\begin{array}{c}\mathrm{SO}_{4} \\
(\mathrm{mg} / \mathrm{L})\end{array}$ & $\begin{array}{c}\mathrm{CL} \\
(\mathrm{mg} / \mathrm{L})\end{array}$ & $\begin{array}{c}\text { Max PM2.5 } \\
\left(\mu \mathrm{g} / \mathrm{m}^{3}\right)\end{array}$ & $\begin{array}{c}\text { Max CO } \\
(\text { ppm per million })\end{array}$ & $\begin{array}{c}\text { Max } \mathrm{SO}_{2} \\
\text { (ppb per million) }\end{array}$ \\
\hline Value & 7.68 & 187 & 123 & 7.7 & 103 & 44.3 \\
\hline
\end{tabular}

Table 2. Active faults and the relevant data.

\begin{tabular}{clccccc}
\hline No. & Fault name & $\begin{array}{c}\text { Length } \\
(\mathbf{k m})\end{array}$ & $\begin{array}{c}\text { Rupture } \\
\text { length } \\
(\mathbf{k m})\end{array}$ & $\begin{array}{c}\text { Maximum } \\
\boldsymbol{M}_{\boldsymbol{s}}\end{array}$ & $\begin{array}{c}\text { Distance from } \\
\text { Azar bridge } \\
(\mathbf{k m})\end{array}$ & $\begin{array}{c}\text { Deterministic PGA } \\
\text { (1000-years ret urn } \\
\text { period) }\end{array}$ \\
\hline 1 & Zefreh & 160 & 16 & 6.5 & 70 & $0.086 \mathrm{~g}$ \\
2 & Kashan & 260 & 26 & 6.75 & 100 & $0.066 \mathrm{~g}$ \\
3 & North-east of Isfahan & 245 & 25 & 6.73 & 22 & $0.415 \mathrm{~g}$ \\
4 & Tiran & 170 & 17 & 6.52 & 60 & $0.106 \mathrm{~g}$ \\
5 & Najaf-Abad & 225 & 23 & 6.68 & 28 & $0.304 \mathrm{~g}$ \\
6 & Mobarake & 180 & 18 & 6.55 & 45 & $0.156 \mathrm{~g}$ \\
7 & South of Isfahan & 165 & 17 & 6.52 & 20 & $0.38 \mathrm{~g}$ \\
8 & Dehaghan & 160 & 16 & 6.5 & 60 & $0.104 \mathrm{~g}$ \\
9 & Sefid Dasht & 190 & 20 & 6.6 & 80 & $0.079 \mathrm{~g}$ \\
10 & Hafshajan & 215 & 22 & 6.66 & 100 & $0.055 \mathrm{~g}$ \\
11 & Zagros & 1350 & 135 & 7.5 & 95 & $0.142 \mathrm{~g}$ \\
12 & Dehshir & 370 & 40 & 6.98 & 260 & $0.016 \mathrm{~g}$ \\
\hline
\end{tabular}




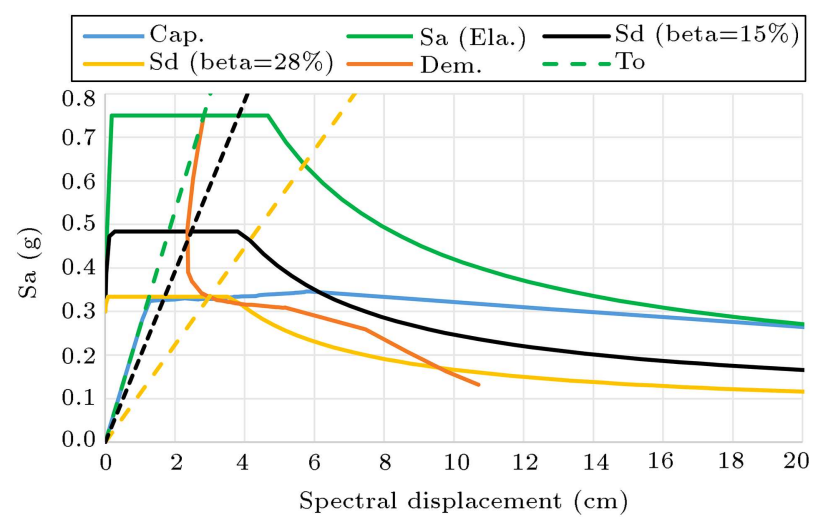

Figure 3. Calculation of performance point associated with the bridge in this study.

longitudinal direction, considering the long span and the direction of the piers, the bridge performance is weaker and needs further investigation. The estimated performance point in the longitudinal direction of the bridge subjected to PGA of design hazard level is shown in Figure 3.

Bridge performance under different levels of seismic hazards is displayed in Table 3. To calculate the elastic spectrum for different hazard levels, the maximum elastic response of the design response spectrum is divided into the acceleration of the design level multiplied by the desired acceleration, but the overall spectrum shape is preserved. After calculating the performance points, the damage state of piers is obtained from the rotational criterion. Results displayed that this bridge will collapse under Maximum Capable Earthquake (MCE) hazard levels.

\subsection{Scour hazard}

In this paper, a series of 100 successive historical datasets on annual peak discharge rates of the Zayandehrood River at the bridge location were collected. Fitting different distribution patterns to the existing data revealed that the lognormal distribution was the best choice for modeling annual peak flow rate. The geometric properties of the river (including its side
Table 4. Deterministic parameters for the estimation of scour depth.

\begin{tabular}{lcc}
\hline \multicolumn{1}{c}{ Parameter } & Designation & Value \\
\hline Bottom width $(\mathrm{m})$ & $b$ & 145 \\
Slope of the bed stream & $s$ & 0.0015 \\
Manning value & $n$ & 0.04 \\
Coefficient for pier nose shape & $k_{1}$ & 1.1 \\
Coefficient for flow angle of & $k_{2}$ & 1.0 \\
attack & & \\
Coefficient for bed material size & $k_{4}$ & 1.0 \\
Pier depth $(\mathrm{m})$ & $D_{p}$ & 3.0 \\
Pier width $(\mathrm{m})$ & $D$ & 2.4 \\
\hline
\end{tabular}

slope and slope of the bed stream) are reported in Table 4. Using these properties and annual peak flow data, flow depth and velocity can be calculated using Eqs. (6) and (7). The values thus obtained can then be used as mean values for their corresponding distributions in Table 4.

Using the information of Table 5 and by generating a series of 1,000,000 Monte Carlo simulations, the annual scour depth was determined using Eq. (5).

\subsection{Carbonation hazard}

As already mentioned, the protective cover reduces in concrete reinforcement with time due to carbonation. Carbonation triggers corrosion in steel bars to make the structure more vulnerable to the increasing damages caused by the propagating corrosion in the underlying layers. Hence, the effects of carbonation on the lifecycle of the structure and its implications for accelerated corrosion should be properly investigated. It is established that the cover depth of the reinforcing bars reduces in time due to carbonation. Valcuende and Parra [32] used Eq. (4) to estimate the carbonation rate to be 0.66 in their concrete specimen N-45-42 (similar to the concrete of the present study).

Table 3. Bridge status under Peak Ground Acceleration (PGA) different levels.

\begin{tabular}{|c|c|c|c|c|c|c|}
\hline \multirow{2}{*}{$\begin{array}{c}\text { Earthquake } \\
\text { intensity } \\
(\mathrm{g})\end{array}$} & \multicolumn{2}{|c|}{ Current status } & \multicolumn{2}{|c|}{$\begin{array}{c}7.5 \% \text { increase in } \\
\text { pier strength }\end{array}$} & \multicolumn{2}{|c|}{$\begin{array}{l}15 \% \text { increase in } \\
\text { pier strengths }\end{array}$} \\
\hline & $\begin{array}{c}\text { Maximum } \\
\text { displacement } \\
(\mathrm{mm})\end{array}$ & $\begin{array}{l}\text { Performance } \\
\text { state }\end{array}$ & $\begin{array}{c}\text { Maximum } \\
\text { displacement } \\
(\mathbf{m m})\end{array}$ & $\begin{array}{l}\text { Performance } \\
\text { state }\end{array}$ & $\begin{array}{c}\text { Maximum } \\
\text { displacement } \\
(\mathrm{mm})\end{array}$ & Performance \\
\hline $\begin{array}{c}0.25 \mathrm{~g} \\
\text { (operation) }\end{array}$ & 20 & IO & 19.4 & IO & 19.4 & IO \\
\hline $\begin{array}{c}0.3 \mathrm{~g} \\
(\mathrm{DBE})\end{array}$ & 31 & IO & 27 & IO & 20 & IO \\
\hline $\begin{array}{l}0.45 \mathrm{~g} \\
(\mathrm{MCE})\end{array}$ & 105 & Collapse & 90 & Collapse & 70 & LS \\
\hline
\end{tabular}


Table 5. Uncertain parameters for the estimation of scour depth.

\begin{tabular}{lcll}
\hline \multicolumn{1}{c}{ Random variable } & Designation & Distribution $[\mathbf{2 , 3 9}]$ & \multicolumn{1}{c}{ Parameter } \\
\hline Coefficient of bed material size & $k_{3}$ & Uniform & {$[1.1,0.05]$} \\
Modeling factor & $\lambda_{p}$ & Asymmetric triangular & {$[0.8,1.0,1.0]$} \\
Flow velocity $(\mathrm{m} / \mathrm{s})$ & $V$ & Symmetric triangular & $C O V=0.28$ \\
Flow depth $(\mathrm{m})$ & $y_{p}$ & Symmetric triangular & COV $=0.1$ \\
Pier width $(\mathrm{m})$ & $D$ & Normal (site-dependent) & Mean $=2.4$, COV $=0.1$ \\
\hline
\end{tabular}

Note: Mean value and coefficient of variation are the parameters used for a uniform distribution. Those for an asymmetric triangular distribution are the lower bound, upper bound, and mode.

Table 6. Statistical parameters involved in the estimation of $T_{\text {corr }}$.

\begin{tabular}{lclcc}
\hline \multicolumn{1}{c}{ Random variable } & Designation & Distribution [29] & Mean & Standard deviation \\
\hline Empirical coefficient of diffusion $\left(\mathrm{mm}^{2} /\right.$ year $)$ & $D_{c}$ & Normal & 220.9 & 25.4 \\
Coefficient of chloride surface concentration & $C_{c r}$ & Normal & 0.8 & 0.1 \\
Model parameter & $A_{c s}$ & Norma & 7.758 & 1.36 \\
Model parameter & $\varepsilon_{c s}$ & Normal & 0 & 1.105 \\
Aging effect factor & $n$ & Beta & 0.362 & 0.245 \\
Correction factor for environmental conditions & $K_{e}$ & Gamma & 0.265 & 0.045 \\
Correction factor for curing time & $K_{c}$ & Beta & 0.8 & 0.1 \\
Correction factor for tests & $K_{t}$ & Normal & 0.832 & 0.024 \\
Model uncertainty coefficient & $X_{1}$ & Lognormal & 1 & 0.05 \\
\hline
\end{tabular}

\subsection{Reinforcement corrosion}

Table 6 lists the values of the model parameters for estimating the corrosion value in the bridge life-cycle. In this way, the probability of corrosion initiation time $\left(T_{\text {corr }}\right)$ in each year was obtained. On the other hand, once corrosion initiates in the following years, the diameter of the bars decreases according to Eq. (1). Accordingly, the Probability Density Function (PDF) of different corrosion levels was obtained. By calculating the area under the curve of the PDF, the cumulative distribution function of corrosion was obtained. Figure 4 illustrates the probability of different corrosion levels while considering carbonation effects during the life-cycle of the bridge. The cover

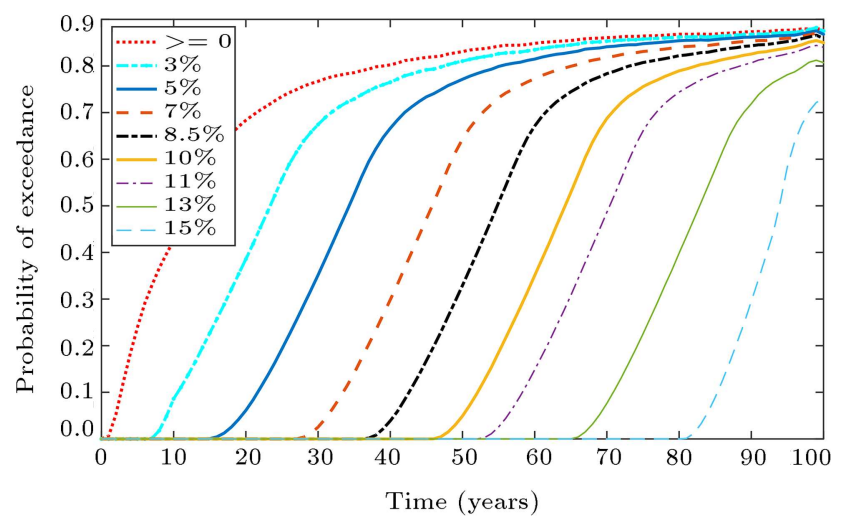

Figure 4. Corrosion probability for different damage levels with the carbonation effects. depth of the concrete reinforcement is reduced as a result of the carbonation process. Reinforcement cover depth $\left(d_{c}\right)$ and diameter of reinforcement bars $\left(d_{b 0}\right)$, parameters for prediction of $T_{\text {corr }}$, are $50 \mathrm{~mm}$ and $26 \mathrm{~mm}$ respectively.

The estimated probabilities in these curves are used in Eq. (10) to compute the total annual loss of the bridge during its life-cycle.

\subsection{Economic losses due to hazards}

In this section, the economic consequences of the hazards are evaluated in terms of the unit of currency. It means that all the damages of the seismic hazard are converted to the cost. The total economic loss is calculated through the following steps:

- Identification of seismic hazard magnitudes and their probabilities;

- Estimation of scour depths at the bridge piers and the probabilities for exceeding a specific scour depth limit;

- Evaluation of different corrosion levels due to carbonation effects and their probabilities;

- Quantification of structural damages caused by earthquake events as well as corrosion and carbonation processes;

- Calculation of the total economic loss resulting from multiple hazards inclusive of an inflation rate of $15 \%$. 
The seismic performance of a bridge for a given ground motion can be evaluated via the pushover analysis. The bridge damages caused by earthquakes can be calculated through the following steps:

- Identification of all possible earthquake events and their annual probabilities of occurrence using the hazard curve;

- Computation of the performance point corresponding to each seismic hazard level.

According to ATC13 [52], each performance level corresponds to a specific loss (Table 7 [52]). Accordingly, the estimated loss costs are obtained by multiplying the loss of each seismic hazard level by the material and construction cost of the bridge. Figure 5 depicts the expected loss curve obtained for a corroded bridge subjected to earthquake and scour events. It indicates loss versus incremental PGA by taking into account specific damage states of corrosion and carbonation as well as possible occurrences of pier scouring.

To illustrate the life-cycle effects of scouring on cumulative damages incurred, the expected life-cycle cost for deteriorating bridge is evaluated based on Eqs. (9) and (10). The results show that the expected total loss of the bridge with a scour tends to be much greater than that of the cases with no scour.

Table 7. Performance levels, damage states, and expected losses ratio [52].

\begin{tabular}{clc}
\hline $\begin{array}{c}\text { Performance } \\
\text { level }\end{array}$ & $\begin{array}{c}\text { Damage } \\
\text { state }\end{array}$ & $\begin{array}{c}\text { Loss magnitude } \\
(\%)\end{array}$ \\
\hline Minor & Slight & 0.5 \\
IO & Light & 20 \\
LS & Moderate & 45 \\
CP & Major & 80 \\
Collapse & Collapse & 100 \\
\hline
\end{tabular}

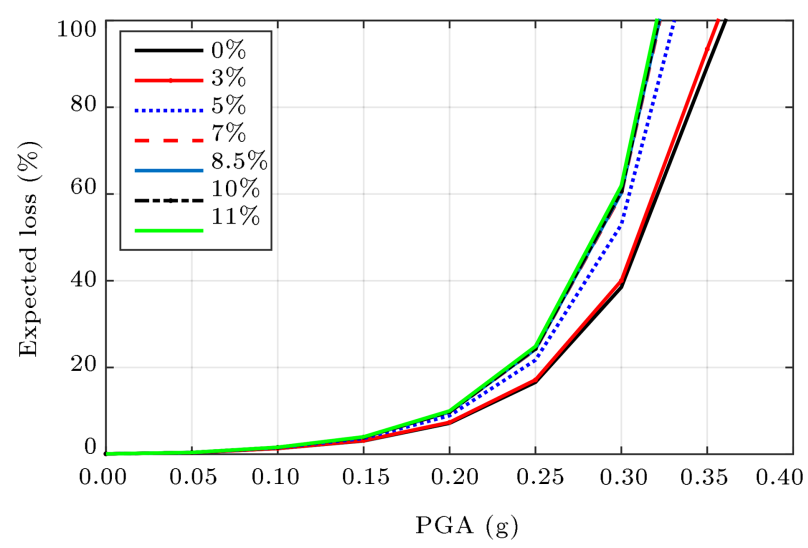

Figure 5. Expected loss curves for a bridge in different percentage of corrosion caused by carbonation and scouring effects.

\section{Cost-benefit analysis of rehabilitation scenarios}

Any bridge rehabilitation program entails both costs and enhanced bridge lifetime benefits. It is important to assess the cost efficiency of each retrofit scenario in order to make the optimal refurbishment decision during bridge life-cycle. The costs associated with a retrofit plan may include the initial construction, maintenance, monitoring, and repair costs as well as road traffic and failure costs (i.e., direct and indirect costs) [53].

The benefit-cost ratio can be used as a criterion to evaluate rehabilitation projects. This criterion is defined as the ratio of the present value of benefits to the present value of operating costs. The Net Present Value (NPV) is defined as the present value of benefits minus the present value of operating costs expressed by Eq. (16) [54]:

$$
N P V=\sum_{t=0}^{T}(B(t)-C(t))(1+r)^{-t} .
$$

The benefit-cost ratio can be calculated as Eq. (17):

$$
\begin{aligned}
\frac{\text { Benefit }}{\text { Cost }} & =\frac{N P V}{C_{\text {capital }}}=\frac{\sum_{t=0}^{T}(B(t)-C(t))(1+r)^{-t}}{C_{\text {capital }}} \\
& =\frac{\sum_{t=0}^{T}\left(C L_{T \text { new }}(t)-C L_{T_{0}}(t)\right)(1+r)^{-t}}{C_{\text {capital }}}
\end{aligned}
$$

where $B(t)$ is the total benefit at time $t$ that can be achieved from the bridge after its rehabilitation, which in this study is the magnitude of reduction in total loss due to the retrofit operations performed on the bridge at time $t$, and $C(t)$ is the total cost of maintenance associated with the bridge at time $t$, which in this study is assumed zero. $C L_{T_{\text {new }}}(t)$ and $C L_{T_{0}}(t)$, respectively, represent the total loss after rehabilitation which arises from hazards if the retrofit plan is not implemented; these values may be calculated using Eq. (10). Finally, $C_{\text {capital }}$ is the total capital cost to be expended for the retrofit plan.

\subsection{Enhancement of design safety factor}

The structural design safety factor is the ratio of the ultimate capacity to the applied load (or a combination of loads) of the component under consideration [49]. The effects of increasing design safety factors related to pier strength on bridge strength against different levels of the earthquake are examined. For this purpose, the structural design safety factor is increased to $7.5 \%$ and $15 \%$ in order to achieve a higher structural strength. This enhancement is accompanied by an increase in 


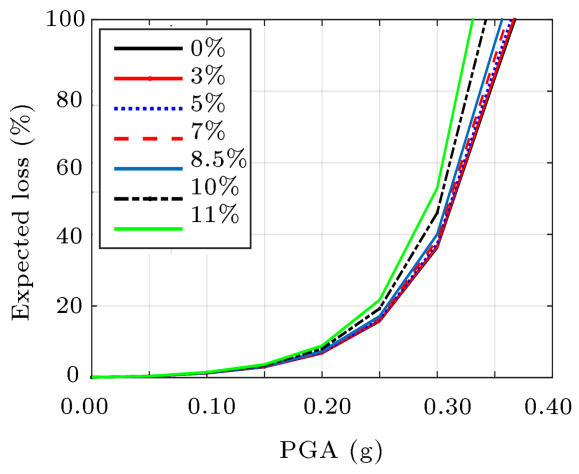

(a)

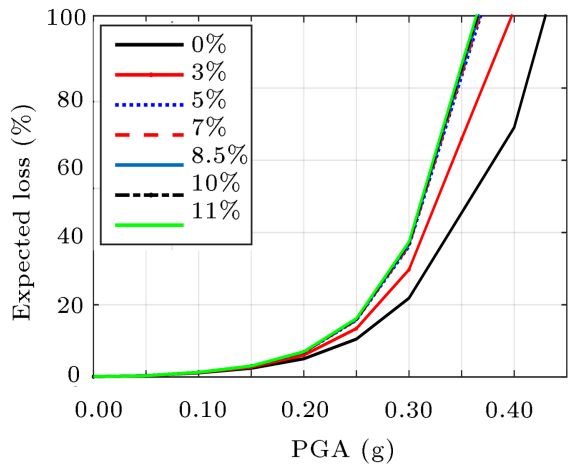

(b)

Figure 6. Expected losses due to earthquake events in a corroded bridge redesigned with increased safety factors combined with carbonation and scour effects: (a) $7.5 \%$ increase and (b) $15 \%$ increase in seismic resistance.

the initial construction cost. This increment in cost can lead to a decrease in the likely loss costs incurred by the earthquake and seismic loads. In this case $C_{I}$ is assumed more than the present value.

\subsection{Using CFRP Sheets (retrofit scenario in the operation stage)}

Buckling-restrained braces can seismically rehabilitate bridges in the transverse direction [55], but the bridge which is the subject of this study is already seismicresistant in the transverse direction. Also, steel jackets are proper tools for shear retrofitting of the bridge [56,57]. Another strategy is to install Carbon Fiber Reinforced composite Plates (CFRP) on bridge piers to strengthen the existing structure under extreme loads and to increase its resistance against steel bar corrosion [58,59]. Experiments which were carried out by Xiao and $\mathrm{Wu}$ [59] revealed that CFRP can increase the compressive strength and ductility of concrete. These fibers are placed with the glue around the piers to increase the flexural strength of the plastic hinges. In this case $C_{M}$ is added to Eq. (10). As mentioned in Section $3, C_{M}$ in Eq. (11) is the maintenance cost which has been adopted as retrofit cost in this study. The cost of CFRP or other retrofit methods is obtained by estimating the cost of materials and construction of each retrofit scenario.

\subsection{Scenario assessment based on the cost-benefit analysis}

The outcomes of each scenario are evaluated using econometric criteria such as incurred extra costs and probably earned profits. Extra cost involves the expenditure of retrofitting materials, and profit value is the reduction in losses caused by damages. Main construction costs of the bridge under study include: total volume of concrete, total steel bar weight, pier casting, deck casting, asphalt and operation costs.

In the first plan aimed at improving the seismic design of the bridge, an increase in rebar area of the piers is entertained and their contribution to the im- proved seismic capacity of the bridge and the possible associated costs are determined. In this strategy, enhanced seismic capacity is expected to lead to reduced damages due to possible earthquakes. The variations in losses incurred by earthquake events combined with scouring and deterioration effects that involved increases of $7.5 \%$ and $15 \%$ in the design safety factor are illustrated in Figure 6(a) and (b), respectively.

Curves in Figure 6 reveal the expected losses associated with PGA and reduced deterioration levels due to bridge strengthening. The costs in the construction stage for this retrofit plan include extra weight of steel bars (kg), which is $2000 \mathrm{~kg}$ and $4000 \mathrm{~kg}$ for $7.5 \%$ and $15 \%$ increase in pier resistance respectively. The unit cost of this parameter is assumed $0.6 \$$.

The reduction in the annual cost of the bridge under the first retrofitting scenario is illustrated in Figure 7(a). This figure also shows the effects of the three hazards of carbonation, corrosion, and scour on the bridge under seismic loads. As already mentioned, the effects of carbonation are included in the reduced cover depth of concrete. Regarding the earthquake, the trend of expected cumulative loss of single-hazard case is highly lower than those of multi-hazard ones. Generally, the expected cumulative losses decline after executing the retrofit plan. CFRP strengthening is expected to stop the corrosion process.

Figure $7(\mathrm{~b})$ shows the expected total cost of the loss in the bridge system when CFRP sheets are used in comparison with the situation in which no retrofit plans are considered. The expected total losses due to damages caused by seismic loads and pier scouring effects decreases under retrofit plans.

Clearly, the $15 \%$ increase in the design safety factor has a significant effect on the enhanced lifetime of the bridge. The performance of the bridge under different levels of PGA is reported in Table 3. Clearly, an enhancement of $15 \%$ in structural strengthening is the minimum requirement to meet the requirements for this bridge. 


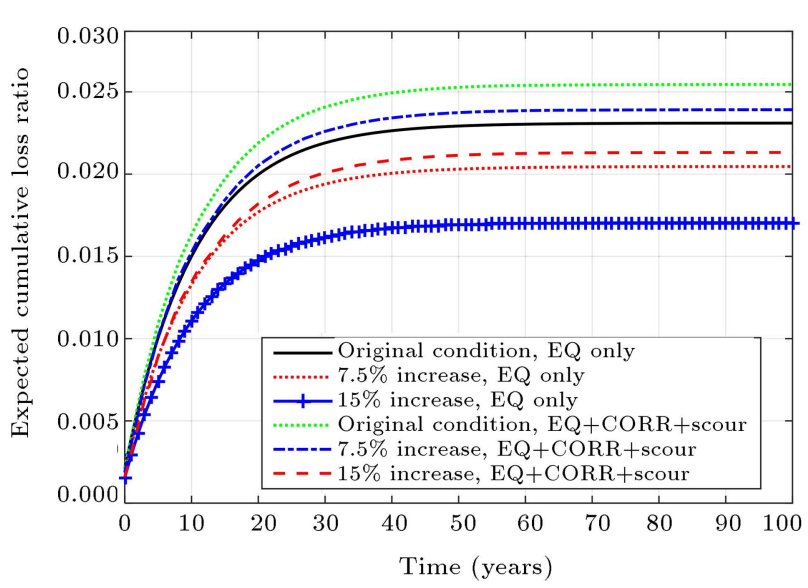

(a)

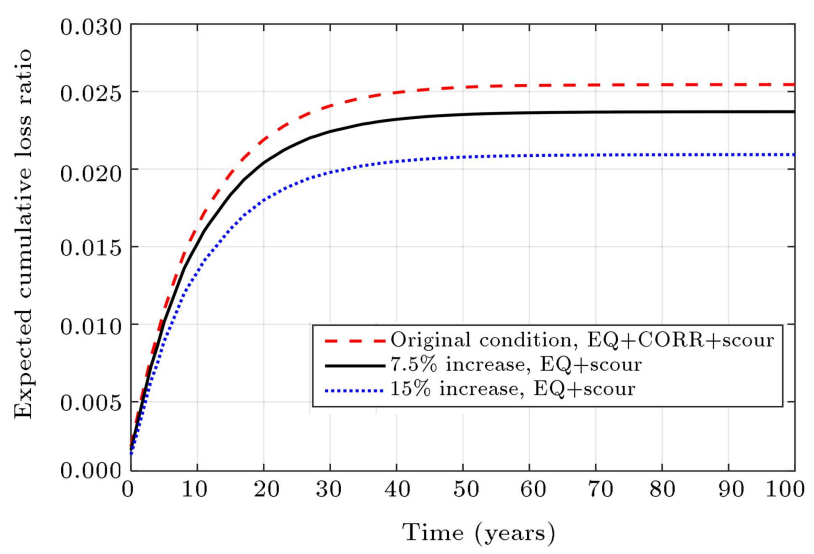

(b)

Figure 7. Changes due to the retrofit plan in the expected cumulative losses ratio of the bridge subjected to multiple hazards: (a) 1st scenario and (b) 2nd scenario.

Retrofitting with CFRP materials is quite effective in strengthening $\mathrm{RC}$ sections to resist higher seismic loads. Also, CFRP sheets can improve upon the structural durability against corrosion. In order to investigate the effectiveness of CFRP on the flexural performance of concrete piers, an enhancement of $7.5 \%$ was considered in the ultimate strength of concrete beams and one of $15 \%$ in pier strength using CFRP strengthening. Cost of the CFRP retrofit plans for $7.5 \%$ and $15 \%$ resistance increase are $7500 \$$ and $9750 \$$ respectively.
Table 8 reports the cost-benefit ratio under the two scenarios. This cost value is the difference between the cumulative losses in the structure before and after the execution of the retrofit scenario. Reliability index $(\beta)$ is estimated based on the failure probability $\left(P_{f}\right)$ under design hazard level $(0.3 \mathrm{~g})$ :

$$
\beta=-\Phi^{-1}\left(P_{f}\right)
$$

The benefit to cost ratio for the CFRP strengthening plan is less than unity. However, the reliability index is inevitable and crucially necessary if the structural performance during a maximum seismic hazard and the subsequent catastrophic consequences like deaths, injuries, low security, traffic, and environmental costs are taken into account. Moreover, given the pivotal role of bridges in the transportation network, interruptions in their transport services will be accompanied by excessive losses.

\section{Conclusions}

To evaluate reinforced concrete bridges deteriorated in their lifetime a comprehensive framework was proposed. This framework is capable of assessing bridges under uncertain multiple hazards of scouring, corrosion, carbonation, and seismic loads. A cost-benefit analysis was performed for the decision making. The expected cumulative loss caused by the hazards was estimated for a range of possible earthquake intensities for all defined scenarios. The uncertainties associated with the estimation of the intensity of each hazard and their occurrence probabilities were included in the assessments. The following conclusions may be drawn from the results of this study:

- The multi-hazard framework proposed in this paper proved to be an effective tool for a more realistic evaluation of the structure's life-cycle;

- The results of applying this multi-hazard framework for evaluating different retrofit scenarios relating to deteriorating bridges suggest that scour, corrosion, and carbonation processes, as well as their combined effects throughout the lifetime of bridges, should be

Table 8. The cost-benefit ratio of the retrofit scenarios.

\begin{tabular}{lccccc}
\hline \multicolumn{1}{c}{ Description } & $\begin{array}{c}\text { Extra } \\
\text { cost } \\
\end{array}$ & $\begin{array}{c}\text { Lifetime } \\
\text { expected loss }\end{array}$ & $\begin{array}{c}\text { Benefit } \\
(\boldsymbol{\%})\end{array}$ & $\begin{array}{c}\text { Benefit/cost } \\
\text { ratio }\end{array}$ & $\begin{array}{c}\text { Reliability } \\
\text { index }\end{array}$ \\
\hline Initial design & - & 2.55 & - & - & -0.85 \\
$7.5 \%$ increase in pier resistance (1st scenario) & 1200 & 2.39 & 960 & 0.8 & 0.46 \\
$15 \%$ increase in pier resistance (1st scenario) & 2400 & 2.13 & 2520 & 1.05 & 1.0 \\
$7.5 \%$ increase in pier resistance (2nd scenario) & 7500 & 2.37 & 1080 & 0.144 & 3 \\
$15 \%$ increase in pier resistance (2nd scenario) & 9750 & 2.09 & 2760 & 0.283 & 5 \\
\hline
\end{tabular}


considered to obtain more accurate assessments of deteriorating bridges during earthquake events and to achieve more accurate estimates of the expected life-cycle damages;

- Cumulative losses of the retrofitted structure with CFRP can be reduced by $18 \%$, which is $1.5 \%$ higher than what could be achieved by using the first scenario, due to stopping the corrosion process by using CFRP retrofitting;

- Bridge collapse typically occurs under maximum expected seismic loads. It is, therefore, inevitable to adopt retrofit measures that enhance the seismic capacity of the structure. The benefit to cost ratio of the CFRP strengthening plant, in this case, was found to be less than one. However, this may be justified if the structural performance and reliability index under seismic loads as well as the social, economic, and environmental consequences are taken into account.

\section{Acknowledgment}

The data presented in this article is from a research study defined by the authors of this paper for the Isfahan municipality to prioritize retrofitting projects. The authors of this article express their gratitude to the municipality of Isfahan.

\section{References}

1. Decó, A. and Frangopol, D.M. "Life-cycle risk assessment of spatially distributed aging bridges under seismic and traffic hazards", Earthquake Spectra., 29(1), pp. 127-153 (2013).

2. Zhu, B. and Frangopol, D.M. "Time-variant risk assessment of bridges with partially and fully closed lanes due to traffic loading and scour", Journal of Bridge Engineering, 21(6), 04016021 (2016).

3. Alipour, A., Shafei, B., and Shinozuka, M. "Reliability-based calibration of load and resistance factors for design of RC bridges under multiple extreme events: Scour and earthquake", Journal of Bridge Engineering, 18(5), pp. 362-371 (2012).

4. Wang, Z., Dueñas-Osorio, L., and Padgett, J.E. "Influence of scour effects on the seismic response of reinforced concrete bridges", Engineering Structures, 76, pp. 202-221 (2014).

5. Guo, X. and Chen, Z. "Life-cycle multihazard framework for assessing flood scour and earthquake effects on bridge failure", ASCE-ASME Journal of Risk and Uncertainty in Engineering Systems, Part A: Civil Engineering, 2(2), C4015004 (2015).

6. Guo, X., Wu, Y., and Guo, Y. "Time-dependent seismic fragility analysis of bridge systems under scour hazard and earthquake loads", Engineering Structures, 121, pp. 52-60 (2016).
7. Takamine, H., Watabe, K., Miyata, H., Asaue, H., Nishida, T., and Shiotani, T. "Efficient damage inspection of deteriorated $\mathrm{RC}$ bridge deck with rain-induced elastic wave", Construction and Building Materials, 162, pp. 908-913 (2018).

8. Cui, F., Zhang, H., Ghosn, M., and Xu, Y. "Seismic fragility analysis of deteriorating RC bridge substructures subject to marine chloride-induced corrosion", Engineering Structures, 155, pp. 61-72 (2018).

9. Akiyama, M., Frangopol, D.M., and Matsuzaki, H. "Life-cycle reliability of RC bridge piers under seismic and airborne chloride hazards", Earthquake Engineering \& Structural Dynamics, 40(15), pp. 1671-1687 (2011).

10. Dong, Y., Frangopol, D.M., and Saydam, D. "Timevariant sustainability assessment of seismically vulnerable bridges subjected to multiple hazards", Earthquake Engineering \& Structural Dynamics, 42(10), pp. 1451-1467 (2013).

11. Kumar, R., Gardoni, P., and Sanchez-Silva, M. "Effect of cumulative seismic damage and corrosion on the life cycle cost of reinforced concrete bridges", Earthquake Engineering and Structural Dynamics, 38, pp. 887-905 (2009).

12. Biondini, F., Camnasio, E., and Palermo, A. "Lifetime seismic performance of concrete bridges exposed to corrosion", Structure and Infrastructure Engineering, 10(7), pp. 880-900 (2014).

13. Shekhar, S., Ghosh, J., and Padgett, J.E. "Seismic lifecycle cost analysis of ageing highway bridges under chloride exposure conditions: modelling and recommendations", Structure and Infrastructure Engineering, 14(7), pp. 1-26 (2018).

14. Gheitasi, A. and Harris, D.K. "Performance assessment of steel-concrete composite bridges with subsurface deck deterioration", Structures, 2, pp. 8-20 (2015).

15. NourEldin, M., Naeem, A., and Kim, J. "Life-cycle cost evaluation of steel structures retrofitted with steel slit damper and shape memory alloy-based hybrid damper", Advances in Structural Engineering, 22(1), pp. 1-14 (2019).

16. Keoleian, G.A., Kendall, A., Dettling, J.E., Smith, V.M., Chandler, R.F., Lepech, M.D., and Li, V.C. "Life cycle modeling of concrete bridge design: Comparison of engineered cementitious composite link slabs and conventional steel expansion joints", Journal of Infrastructure Systems, 11(1), pp. 51-60 (2005).

17. Dennemann, K.L. "Life-cycle cost-benefit (LCC-B) analysis for bridge seismic retrofits", Rice University (2010).

18. Padgett, J.E., Dennemann, K., and Ghosh, J. "Riskbased seismic life-cycle cost-benefit (LCC-B) analysis for bridge retrofit assessment", Structural Safety, 32(3), pp. 165-173 (2010).

19. Frangopol, D.M. "Life-cycle performance, management, and optimisation of structural systems under 
uncertainty: accomplishments and challenges", Structure and Infrastructure Engineering, 7(6), pp. 389-413 (2010).

20. Padgett, J.E. and Tapia, C. "Sustainability of natural hazard risk mitigation: Life cycle analysis of environmental indicators for bridge infrastructure", Journal of Infrastructure System, 19(4), pp. 395-408 (2013).

21. Frangopol, D.M. and Soliman, M. "Life-cycle of structural systems: recent achievements and future directions", Structure and Infrastructure Engineering, 12(1), pp. 1-20 (2016).

22. Ranjkesh, S.H., Asadi, P., and Hamadani, A.Z. "Seismic collapse assessment of deteriorating RC bridges under multiple hazards during their life-cycle", Bulletin of Earthquake Engineering, 17(9), pp. 5045-5072 (2019).

23. Li, Y. and Li, H. "Interactive evolutionary multiobjective optimization and decision-making on lifecycle seismic design of bridge", Advances in Structural Engineering, 21(15), pp. 2227-2240 (2018).

24. Wang, Y., Ibarra, L., and Pantelides, C. "Collapse capacity of reinforced concrete skewed bridges retrofitted with buckling-restrained braces", Engineering Structures, 184, pp. 99-114 (2019).

25. Gromala, D., Kapur, O., Kochkin, V., Line, P., Passman, S., Reeder, A., and Trusty, W., Natural Hazards and Sustainability for Residential Buildings, FEMA, Washington, DC (2010).

26. Ang, A.S. "Life-cycle considerations in risk-informed decisions for design of civil infrastructures", In LifeCycle Civil Engineering, CRC Press, pp. 23-30 (2008).

27. Ghosh, J. and Padgett, J.E. "Aging considerations in the development of time-dependent seismic fragility curves", Journal of Structural Engineering, 136(12), pp. 1497-1511 (2010).

28. Kumar, R. and Gardoni, P. "Stochastic modeling of deterioration in buildings and civil infrastructure", In Handbook of Seismic Risk Analysis and Management of Civil Infrastructure Systems, Woodhead Publishing, pp. 410-434 (2013).

29. Ellingwood, B.R. "Risk-informed condition assessment of civil infrastructure: state of practice and research issues", Structure and Infrastructure Engineering, 1(1), pp. $7-18$ (2005).

30. Choe, D.E., Gardoni, P., Rosowsky, D., and Haukaas, T. "Probabilistic capacity models and seismic fragility estimates for RC columns subject to corrosion", Reliability Engineering \& System Safety, 93(3), pp. 383-393 (2008).

31. Hussain, S., Bhunia, S., and Singh, S.B. "Comparative study of accelerated carbonation of plain cement and fly-ash concrete", Journal of Building Engineering, 10, pp. 26-31 (2017).

32. Valcuende, M. and Parra, C. "Natural carbonation of self-compacting concretes", Construction and Building Materials, 24(5), pp. 848-853 (2010).
33. Revert, A.B., De Weerdt, K., Hornbostel, K., and Geiker, M.R. "Carbonation-induced corrosion: Investigation of the corrosion onset", Construction and Building Materials, 162, pp. 847-856 (2018).

34. Jung, K.S. and Frangopol, D.M. "Life-cycle reliabilitybased maintenance cost optimization of deteriorating structures with emphasis on bridges", Journal of Structural Engineering, 129(6), pp. 818-828 (2003).

35. Federal Highway Administration (FHWA) "Evaluating scour at bridges", Hydrauicl Engineering Circular, No. 18 (HEC-18), 4th Ed., Washington, DC (2001).

36. Manning, R., Griffith, J.P., Pigot, T., and VernonHarcourt, L.F. "On the flow of water in open channels and pipes", Transactions Institution of Civil engineers of Ireland, 20, pp. 161-207 (1890).

37. Johnson, P.A. "Comparison of pier-scour equations using field data", Journal of Hydraulic Engineering, 121(8), pp. 626-629 (1995).

38. Johnson, P.A. "Uncertainty of hydraulic parameters", Journal of Hydraulic Engineering, 122(2), pp. 112-114 (1996).

39. Johnson, P.A. and Dock, D.A. "Probabilistic bridge scour estimates", Journal of Hydraulic Engineering, 124(7), pp. 750-754 (1998).

40. Ghosn, M., Moses, F., and Wang, J. "Design of highway bridges for extreme events", NCHPR Rep. 489, Transportation Research Board, Washington, DC (2003).

41. Buckle, I.G., Friedland, I.M., Mander, J.B., Martin, G.R., Nutt, R., and Power, M., Seismic Retrofitting Manual for Highway Structures: Part 1-bridges (2006).

42. Wen, Y.K. and Kang, Y.J. "Minimum building lifecycle cost design criteria. I: Methodology", Journal of Structural Engineering, 127(3), pp. 330-337 (2001).

43. Ghasemi, S.H. and Nowak, A.S. "Target reliability for bridges with consideration of ultimate limit state", Engineering Structures, 152, pp. 226-237 (2017).

44. CSI Analysis Reference Manual for Sap2000, ETABS, SAFE and CSiBridge, Computers and Structures, Inc., Berkeley, California, USA (2011).

45. Priestley, M.J.N., Seible, F., and Calvi G.M., Seismic Design and Retrofit of Bridges, Wiley, NY (1996).

46. Banerjee, S. and Shinozuka, M. "Nonlinear static procedure for seismic vulnerability assessment of bridges", Computer-Aided Civil and Infrastructure Engineering, 22(4), pp. 293-305 (2007).

47. ATC-40 "Seismic evaluation and retrofit of concrete buildings", Applied Technology Council, Redwood City (1996).

48. Imbsen, R.A. "AASHTO guide specifications for LRFD seismic bridge design", American Association of State Highway \& Transport Officials, Subcommittee for Seismic Effects on Bridges (2007).

49. Specifications "AASHTO-LRFD Bridge Design", American Association of State Highway and Transportation Officials, Washington, DC (2012). 
50. Zare, M., Ghafory-Ashtiany, M., and Bard, P. "Attenuation law for the strong-motions in Iran, Proc.", 3th Inernational Conference on Seismology and Earthquake Engineering (1999).

51. Zare, M., Karimi-Paridari, S., and Sabzali, S. "Spectral attenuation of strong motions for near source data in Iran", Journal of Seismology and Earthquake Engineering, 10(3), p. 147 (2008).

52. Applied Technology Council "ATC-13: Earthquake damage evaluation data for California", Applied Technology Council (ATC), Redwood City, CA. 492, (1985).

53. Priestley, M.N., Seible, F., and Calvi, G.M., Seismic Design and Retrofit of Bridges, John Wiley \& Sons (1996).

54. Boardman, A.E., Greenberg, D.H., Vining, A.R., and Weimer, D.L., Cost-Benefit Analysis: Concepts and Practice, Cambridge University Press (2017).

55. Wang, Y., Ibarra, L., and Pantelides, C. "Seismic retrofit of a three-span RC bridge with bucklingrestrained braces", Journal of Bridge Engineering, 21(11), p. 04016073 (2016).

56. Priestley, M.N., Seible, F., and Xiao, Y. "Steel jacket retrofitting of reinforced concrete bridge columns for enhanced shear strength-Part 2: Test results and comparison with theory", Structural Journal, 91(5), pp. 537-551 (1994).

57. Xiao, Y. and $\mathrm{Wu}, \mathrm{H}$. "Retrofit of reinforced concrete columns using partially stiffened steel jackets", Journal of Structural Engineering, 129(6), pp. 725-732 (2003).

58. Gergely, J., Pantelides, C.P., and Reaveley, L.D. "Shear strengthening of RCT-joints using CFRP com- posites", Journal of Composites for Construction, 4(2), pp. 56-64 (2000).

59. Xiao, Y. and $\mathrm{Wu}, \mathrm{H}$. "Compressive behavior of concrete confined by carbon fiber composite jackets", Journal of Materials in Civil Engineering, 12(2), pp. 139-146 (2000).

\section{Biographies}

Payam Asadi is an Assistant Professor in Department of Civil Engineering at Isfahan University of Technology, Isfahan, Iran. He received his BS, MS, and PhD degrees in Civil Engineering from Sharif University of Technology, Iran. His research interests are in the areas of earthquake engineering, structural dynamics, and life-cycle sustainability design of structures.

Somayeh Hamed Ranjkesh received her MSc in Industrial Engineering from Sharif University of Technology, Iran and $\mathrm{PhD}$ in Systems and Industrial Engineering from Isfahan University of Technology, Iran. Her current research interests include reliability modeling of deteriorating systems subjected to shocks and maintenance decision-making.

Ali Zeinal-Hamadani is a Professor in Department of Industrial Engineering at Isfahan University of Technology, Isfahan, Iran. His research interests are in the areas of statistics, quality control, multivariate statistical analysis, data mining and reliability modeling. He has numerous publications in international journals and conferences. 